\title{
Smartphone Addiction, Sleep Quality and Mechanism
}

\section{Mehrnaz Moattari ${ }^{1}$, Farahnaz Moattari ${ }^{2 \#^{*}}$, Gholamreza Kaka ${ }^{3}$,Homa Mohseni Kouchesfahani ${ }^{1 H^{*}}$, Seyed Homayoon Sadraie ${ }^{3}$ and Majid Naghdi ${ }^{4}$}

\author{
${ }^{1}$ Department of Animal Biology, Faculty of Biological Science, Kharazmi University, Tehran, Iran \\ ${ }^{2}$ Faculty of Agriculture and Natural Resources, Persian Gulf University, Bushehr, Iran \\ ${ }^{3}$ Neuroscience Research Center, Baqiyatallah University of Medical Sciences, Tehran, Iran \\ ${ }^{4}$ Fasa University of Medical Science, Fars, Iran \\ ${ }^{\#}$ Equally contributed in this work.
}

*Corresponding author: Homa Mohseni Kouchesfahani, Department of Animal Biology, Faculty of Biological Science, Kharazmi University, PO. Box: 15719-14911, Tehran, Iran, Tel/Fax: +982126127286, Tel: +989123844874;

Farahnaz Moattari, Faculty of Agriculture and Natural Resources, Persian Gulf University, Bushehr, Iran

\begin{abstract}
Addiction refers to "loss of control" and "despite adverse consequences". Substance-free addiction (or behavioral addiction) covers pathological gambling, food addiction, internet addiction, and mobile phone addiction. Nowadays, much has been said about new Medias and technologies addiction that connect us and make us lonely at the same time, consequently, leads to adverse mental health disadvantageous. Smartphones are increased rapidly as an indispensable member of our everyday life for most people, especially students all over the world. Smartphones provide users with internet-based communication, business trading, education, entertainment media, and even clinical applications; thus, smartphone use must share many functional or psychological properties with internet use. Mobile technology addiction is driven by the human urge to connect with people, and the related necessity to be seen, heard, thought about, guided, and monitored by others, that reaches deep in our social brains and far in our evolutionary past. Internet-based technologies addiction can eventually lead to individual social and psychological damage, accompanied by somatic symptoms.

This study aimed to explain definition, classification of addiction emphasizing on substance-free type of addiction (here, smartphone technology) and the neurophysiological mechanisms that underlie this kind of addiction disorders. In sleep deprivation affects higher sympathetic activity. After those two important hormones, leptin (a hormone contributing to satiety perception) and ghrelin (a hormone contributing to energy expenditure) affect the homeostatic center in hypothalamus and reward centers and thus modulates orexinergic neurons which connect between sleep and food intake.
\end{abstract}

\section{Keywords}

Addiction, Sleep, Smartphone

\section{Introduction}

\section{Definition of addiction}

The term of addiction is difficult to define, and the concept of addiction has been reflected as debatable; however, the most important definition of addiction is the dependence on a substance or activity [1].

\section{Behavioral addiction versus substance addiction}

There are 2 types of addiction, one is drug addiction such as alcohol; caffeine; cannabis; hallucinogens; inhalants; opioids; sedatives, hypnotics, and anxiolytics; stimulants; and tobacco and the other is action behaviors such as game, internet, even smartphone. Current criteria for diagnosis are included in the Diagnostic and Statistical Manual of Mental Disorders (DSM-V). These include: 1) Taking longer time than intended; 2) A persistent desire and lack of control the use of the drug/ substance; 3) Spending a lot of time in activities necessary to use drug/substance; 4) A strong desire to use the drug/substance; 5) Recurrent use results in failure achievement in homework; 6) Continued use despite recurrent social or interpersonal problems; 7) Important social and occupational activities are reduced because 
of drug/substance use; 8) Recurrent use and physically hazardous; 9) Drug/substance use is continued despite knowledge of having a persistent or recurrent physical or psychological problem; 10) Tolerance, as defined by either of the following: a) A need for markedly increased amounts of drug/substance to achieve intoxication or desired effect; b) A markedly reduced effects with continued use of drug/substance; 11) Withdrawal, as manifested by either of the following: a) The characteristic withdrawal syndrome for drug/substance; b) Drug/substance is taken to relieve or avoid withdrawal symptoms [2]. Upon Peele's description, some authors have changed the description of addiction from the abuse of a chemical intoxicant or substance $[3,4]$. Based on the $5^{\text {th }}$ Edition of the Diagnostic and Statistical Manual (DSM-5) which its goal is to provide a common clinical language for mental health problems, the term "Substance-Related Disorders" changed to "Substance-Related and Addictive Disorders" [5]. When a behavior provides a satisfaction to an individual, it is actively continued and habituated [6].

Behavior science experts believe that any source which is capable of stimulating an individual could become addictive. Previously defined, problematic use could be included in the behavior addiction category when the following components are taken into consideration: 1) The individual is preoccupied with a specific behavior (smartphone use); 2) The behavior is used in order to escape reality or create a feeling of euphoria; 3) As the behavior is continued, tolerance develops; 4) When the behavior is abstained or interfered with, withdrawal symptoms occur (feeling anxious, depressed, or irritable, obsessive thoughts [7]) and seclusion; 5) As a consequence of the continuous behavior, interpersonal problems occur; and 6) Individual experiences relapse against one's will [8]. Emotional complaints, conflicts in group affairs, college complications including learning problem and deficiency of concentration on doing assignment, professional or interactive complications, seclusion and inattention of contacts and interpersonal or personal duties, and psychological or physical agitation. In cases when the individual does not continue a particular manner, extreme exhaustion, daily life fluctuations, considerably condensed somatic motion, lack and fluctuations in sleep arrangements, intolerance, sexual deviances, viciousness, eating complaint and withdrawal signs [9].

Individuals who have behavioral addiction define addiction-specific occurrences and diagnostic conditions such as intensive desire, unwarranted activities, psychosomatic withdrawal signs, a feeling of lack of loss of control, increased behavior range and recognizing anticipated psychotropic effects (e.g., compulsive gamblers simultaneously use numerous slot machines) [10].

Lack of physical signs of drug addiction in behavioral addiction is the difference between these two kinds of addictions [7]. Substance dependence as well as psychopathological signs including unhappiness, or withdrawal, and social anxiety and absent of social support lead to beginning of behavioral addiction [9]. Risk factors which lead to behavioral addiction are including exhausted, depressed, isolated, reserved, nervous, and usually have other types of addiction [11]. In the aspect of neurochemical view, there is a similarity between drug and behavioral addiction. Both indirectly affect the rewarding response for example through 'dopaminergic system' which participates in development and maintenance of drug - and behavioral addictions [12].

A number of experts believe that behavioral addictions can be passive (e.g. television) or active (e.g. computer games), and usually changing from habits into inducing and obligatory features which may contribute to the development of addiction [13].

Technological addiction as a type of non-chemical behavioral addiction that involves human-machine interaction [14]. Above-mentioned, the definition of drugor behavioral addiction, the components of technological addiction are the same as those of substance addiction or gambling addiction. Here, we focused on smart phone addiction as a type of technological addiction.

\section{Smartphone addiction}

Cell phone addiction consists of four main components: obsessive phone use, behaviors such as repetitive checking for messages or updates; tolerance or longer and more intense of use; withdrawal or feelings of agitation or suffering without the phone; and functional impairment or interference with other life activities and face to face social relationships [15]. All these are very similar to the characteristics of internet addiction [16].

Smartphones are no longer considered simply as "mobile or cell phones", based on the Internet and have a wide range of functions. This real-time information providers and powerful portable computers. In addition to making phone calls, users are able to play games, chat with friends, use messenger systems, access web services (e.g., blogs, homepages, social networks), and search for information [17].

\section{Internet fuels smartphone addiction}

Smartphones involves an extensive range of mobile applications for information, communication skills such as message, e-mail, education, and amusement purposes. Smartphones are becoming progressively essential in individuals and societies' lives. Smartphones have facilities such as touch screens, mobile Internet access via Wi-Fi or social networks, ability for installation of smartphone applications, and involving media players, digital cameras, and GPS-based navigation make it popular.

Smartphone addiction has many aspects that are similar to those of internet addiction and as such the internet addiction criteria must be considered when 
developing smartphone addiction criteria [16]. Dr. Ivan Goldberg first described the term internet addiction disorder (IAD) for pathological, obsessive internet use [18]. Internet addiction is an overarching term characterizing five problematic Internet-related issues: cyber sexual addiction, cyber relationship addiction, net obligations, information overload, and addiction to interactive computer games [19]. Symptoms of internet addiction include social isolation, family conflict, divorce, academic failure, job loss and debt [19].

Internet addiction is described as the inability to control one's internet use and is a condition that results in the serious impairment of various life functions [20]. The psychological consequences involve the following: obsession for the internet or internet gaming; imbalance of real-life relationships, sleep, work, and education [21,22]; increased aggression, hostility, and stress $[23,24]$; problems with verbal memory and attention [23-25]; maladaptive coping strategies [26,27]; and low well-being and high loneliness [28].

Approached form the early previous studies, the research has offered the reason why people are addicted to the internet. Internet addiction have relevance to 3 factors, that is specific characteristics of the internet, personal psychological and emotional characteristics and social-environmental characteristics [29].

Generally people who have psychological and emotional characteristics such as depression, loneliness, social anxiety, impulsivity, distraction [30] easily to addict the internet. The place where internet access, the degree of time to use internet, peer relationships parenting types are also associated the addiction.

Internet addiction can be divided into six types: 1 ) Online game addiction; 2) Cyber-relational addiction; 3) Cyber-sexual addiction; 4) Information overload; 5) Cyber-impulse act, and 6) Computer-technology addiction.

The criteria to differentiate normal from pathological addictive internet use were defined by Young who identified eight questions for internet addiction according to 10 criteria for pathological gambling in the DSM-IV: 1) Do you feel preoccupied with the internet (think about previous on-line activity or anticipate the next on-line session)? 2) Do you feel the need to use the internet with increasing amounts of time in order to achieve satisfaction? 3) Have you repeatedly made unsuccessful efforts to control, cut back, or stop internet use? 4) Do you feel restless, moody, depressed, or irritable when attempting to cut down or stop internet use? 5) Do you stay on-line longer than originally intended? 6) Have you jeopardized or risked the loss of significant relationship, job, educational or career opportunity because of the internet? 7) Have you lied to family members, therapists, or others to conceal the extent of involvement with the internet? 8) Do you use the internet as a way of escaping from problems or for relieving a dysphoric mood (e.g., feelings of helplessness, guilt, anxiety, depression)? Patients were considered "addicted" when answering "yes" to five (or more) of the questions [31].

Internet addiction leads to physical and psychological problems. It provokes physical symptoms such as dry eyes, carpal tunnel syndrome, repetitive motion injuries, wrists, neck, back and shoulders, migraine headaches and numbness and pain in the thumb and the index and middle fingers.

\section{Smartphone addiction: Definition, diagnosis and ad- verse effects}

Smartphones can be problematic when used excessively. For example, excessive smartphone use can cause maladaptive behavioral difficulties seen in impulse control disorders in general or pathological gambling; it can interfere with school or work [32], decrease real-life social interaction, decrease academic ability, cause relationship problems [33], and cause physical health-related problems including blurred vision and pain in the wrists or the back of the neck [34].

To define a new target of addiction, it is said that there is no definition according to the Fifth Edition of Diagnostic and Statistical Manual of Mental Disorders (DSM-5) which differ between behavioral and drug addiction. Only online gambling has been classified in DSM-5. And activities such as video games, exercise, food, shopping, work, and the Internet in general and particularly gambling are classified as behavioral addiction. Since smartphone excessive use and internet addiction have overlaps with each other, De-Sola Gutierrez, et al. proposed similar features in these two kinds of addictions [35].

The Smartphone Addiction Scale (SAS) takes a smartphone's characteristics into consideration [34]. And contains six subscales of problematic smartphone usage (daily-life-disturbance can be defined as having a hard time concentrating in class or while working, pain on the wrists or at the back of the neck, and sleeping disturbance., positive-anticipation is described as feeling excited about smartphone use, even feeling empty without a phone., withdrawal, is represented as being impatient and intolerable without a smartphone, and becoming irritated when bothered while using a mobile phone., overuse; refers to the uncontrollable use of a smartphone., tolerance is represented as always trying to control one's phone use but usually failing to do so., and cyberspace-oriented relationship mainly involves questions about one's relationships obtained via phone technology). This scale was proven to be relatively reliable and valid, and it has been extensively applied to different kinds of modified versions $[36,37]$ around the world. The SAS also yields a total score that is reveals the severity of smartphone addiction; higher scores indicate more severe addictions [34]. 
Lin, et al. defined a list of diagnostic criteria for smartphone addiction which classified in 3 categories:

Category (criteria A): consisted of the symptoms of smartphone addiction including:

1. Persistent use of smartphone with lack of control.

2. Restlessness, nervousness, or irritability after a period of withdrawal from use.

3. Using the smartphone for a period longer than anticipated.

4. Craving and/or unsuccessful efforts to quit or reduce smartphone use.

5. Lack of control and continued using or quitting smartphone use.

6. Persistent smartphone uses without attention to recurrent physical or psychological consequences.

The second category (criteria B) described the functional impairment (two (or more) of the following symptoms have been present) which was secondary to smartphone use, including:

1. Excessive use and subsequently persistent or recurrent physical or psychological problems.

2. Use of smartphone in a physically hazardous situations (such as while driving or crossing the street) or situations that have other negative influences on daily life.

3. Use of smartphone in a way that harms social interactions or activity at school or work.

4. Use of smartphone in a way without attention to spending time which can be lead to or causes suffering [15].

Smartphone users are tempted to use smartphone because it is informative, accessible device. Previous researches suggested that there is a correlation between depression and excessive texting, social networking, gaming, viewing video clips, emailing, and listening to music, which can all be accessed via a smartphone. These results showed that there is a significant increase in smartphone excessive and obsessive usage and increase in users' stress. The increased "technostress" among smartphone users and obsessive usage are positively correlated with anxiety in social communication, locus of control, materialism, and a need for communicate and touch [38].

The final category (criterion C): Was the exclusion criteria to rule out manic episodes or by bipolar I disorder and obsessive-compulsive disorder (OCD) [15]. It is reported that smartphone addiction leads to reduction of academic accomplishment [39]. In addition, smartphone addiction leads to headache, backache, eye strain [40]. It is reported that long term use of social networking sites among Malaysia University [41].
Students was accompanied to decrease of their mental health and this may lead to smartphone addiction [42]. Smartphone addiction also leads to anxiety and depression among university student [43]. Mentioned complications can lead to sleep problems. Many studies reported that long term use of smartphone are accompanied to complaints about phone ringing (ringxiety) problems [44], Nomophobia (No Mobile Phone Phobia) and fear of missing out (FoMo) which means that users feels disconnected from the world if their smartphones are out of reach [45]. It is reported that checking messages through smartphones leads to anxiety among users who are restricted to use this kind of communication [46].

\section{Excessive smartphone usage and sleep quality}

It has been reported that problematic Internet use may affect sleep quality, due to reducing rapid eye movement (REM) sleep, slow-wave sleep, and sleep efficiency [23], or suppressing onset time of melatonin secretion and delay in the beginning of sleep due to the bright light of a computer screen at midnights [47]. The relationship between poor sleep and problematic new medias and technologies such as smartphones are suggested as follows. 1) Displace of smartphones and internet-based technologies instead of regular sleep; 2) Noxious cognitive, emotional or physiological effects of using smartphones and internet-based technologies; 3 ) Light emission from the screen of mentioned devices may affect sleep quality; and 4) Using mobile and generally, internet-based technologies in the bedroom may disturb sleep quality by means of microwaves and also, receiving messages may awake users at night [48]. In this regard, it is reported that the adverse effect of electromagnetic fields released by smartphones on sleep quality through electroencephalograms [49]. Information and communication electronic devices interfere with chronotype or circadian clock by emitting bright light by delay this endogenous clock and causes sleep disturbance. There was an inverse relation between Smartphone ownership and sleep duration and also positive correlation with sleep difficulties. Also, there is a positive relation between eveningness preference and internet addiction and positive correlation between morning persons and traditional media users [50]. Sleep quality had showed that has similar effects on Internet and smartphone users because in both groups, users are exposed to bright light of the screens or electromagnetic radiations. Similarly, it is reported that using smartphones may affect physiological factors on brain activity such as sleep quality and the melatonin rhythm, particularly that of the pineal gland; it may also result in altered cerebral blood flow and brain electrical activity through electromagnetic field exposure in the evenings [51]. Moreover, it is reported that long-term use of mobile devices may lead to physical discomfort, such as muscle pain and headaches, which can adverse effects on 
sleep quality [52]. There was a relation between gender and sleep quality in smartphone users. In this regard, it was reported that number of male users with poor sleep quality was more than good sleep quality. Also, number of sleep latency was higher in smartphone users but there was no relation between smartphone owners and sleep disturbance [53]. Exposure to electronic devices had adverse effects on sleep duration, sleep onset and sleep efficiency. Checking the smartphone is informative and a sign of addiction that can be done repeatedly and is affected by sleep quality because this habit activates reward centers [54]. Medical students use smartphone because of its apps and this affects their sleep quality by increasing depletion in the next morning and this had adverse effects on daily work quality [55].

In addition, sleep disturbance and stress has disadvantageous for physical and psychological health and performance, such as obesity and lower school grades [56].

\section{Sleep deprivation links obesity: The possible mech- anism}

Several explanations have been described the sleep-obesity relationship: i) Added time awake provides more opportunity to eat; ii) Increased hunger from hormones signalling appetite and reduced satiety from hormones promoting satiation; Leptin by itself increases energy expenditure [57]; It is reported that changes in leptin after sleep deprivation would affect both caloric intake and energy expenditure. Gherlin a hormone promoting hunger, increases with sleep restriction, whereas leptin, a hormone contributing to satiety perception, decreases [58]; iii) Altered thermoregulation; decreased body temperature has been shown in conditions of prolonged total sleep deprivation [59]; and iv) Increased fatigue, implying lower physical activity level [60]. Sleep loss and fatigue increase sedentary life and therefore decrease both exercise and nonexercise energy expenditure under real life conditions [61].

\section{Orexin neurons and food intake}

Generally, there is a relationship between sleep and feeding. In this regard, an upregulation of the activity of orexin neurons and changes in appetite-regulating hormones may affect food intake. Orexigenic neurons, which represents the link between sleep and feeding, regulate the fhedonic feeding mediated by the 'reward centers' (ventro-tegmental area and nucleus accumbens) [62]. Leptin and ghrelin are peripheral signals directly interacting with the arcuate nucleus, and ultimately modulating the orexin system activity to decrease and increase food intake, respectively. Their secretion is also modulated by the autonomic nervous system activity. A shift of the sympathovagal balance to higher sympathetic activity has been observed in studies of sleep deprivation $[63,64]$.

\section{Conclusion}

A main feature of the smartphone is the operation of internet-based applications. This study considered novel and noteworthy phenomena: Internet and smartphone addictions. Little research has cast light on these issues, despite the increasing negative influence of these addictions on our lives. Reliability problems of self-reporting formats, and culturally limited studies, make some researchers still cast doubt on diagnosis of internet addiction, the disorder is now considered as one of the behavior addictions [65]. Indeed, internet addiction rooted smartphone addiction but generally smartphone addiction can be happen because it is an information and communication electronic device. As development of internet-based smart-mobile devices increases, the significance of this research is likely to increase. It is suggested, rather, that smartphone usage is the social expectations and rewards of connecting with other people and seeking to learn from others that induce and sustain addictive relationships with smartphones. Smartphone addiction is as the same as drug addiction and can be diagnosed by four properties: compulsion, functional impairment, tolerance, and withdrawal. Smartphone addiction is defined as the lack of control to use the smartphone despite adverse effects including financial, psychological and physical, social harmful consequences on users. About psychological effects of cell Phone Addiction, in this review we mentioned the correlation of smartphone addiction and sleep disturbance which can be as a consequence of increase in sleep disorders and fatigue in users, also, it can be affected by bright light which may decrease sleep quality. Sleep deprivation can act through arcuate nucleus and reward centers such as ventro-tegmental area and nucleus accumbens. The orexin system activity modulates the decrease in energy consumption and increase in food intake which leads to obesity.

\section{References}

1. Widyanto L, McMurran M (2004) The psychometric properties of the internet addiction test. Cyberpsychology Behav 7: 443-450.

2. Association AP (2013) Diagnostic and statistical manual of mental disorders (DSM-5®). American Psychiatric Pub.

3. Griffiths MD (1999) Internet addiction: Internet fuels other addictions. Student Br Med J 7: 428-429.

4. Young KS (2004) Internet addiction: A new clinical phenomenon and its consequences. Am Behav Sci 48: 402-415.

5. Grant JE, Chamberlain SR (2016) Expanding the definition of addiction: DSM-5 vs. ICD-11. CNS Spectr 21: 300-303.

6. Mok JY, Choi SW, Kim DJ, Choi SJ, Lee J, et al. (2014) Latent class analysis on internet and smartphone addiction in college students. Neuropsychiatr Dis Treat 10: 817-828.

7. Davis RA (2001) A cognitive-behavioral model of pathological internet use. Comput Human Behav 17: 187-195.

8. Griffiths M (2005) A 'components' model of addiction within a biopsychosocial framework. J Subst Use 10: 191-197. 
9. Alavi SS, Maracy MR, Jannatifard F, Eslami M (2011) The effect of psychiatric symptoms on the internet addiction disorder in Isfahan's University students. J Res Med Sci 16 793-800.

10. Alavi SS, Eslami M, Meracy MR, Najafi M, Jannatifard F, et al. (2010) Psychometric properties of Young internet addiction test. Int J Behav Sci 4: 183-189.

11. Chebbi P, Koong KS, Liu L, Rottman R (2001) Some observations on internet addiction disorder research. J Info Sys Educ 11: 3-4.

12. Holden C (2001) 'Behavioral'addictions: Do they exist? Science 294: 980-982.

13. Alavi SS, Ferdosi M, Jannatifard F, Eslami M, Alaghemandan $\mathrm{H}$, et al. (2012) Behavioral addiction versus substance addiction: Correspondence of psychiatric and psychological views. Int J Prev Med 3: 290-294.

14. Griffiths M (1996) Gambling on the Internet: A brief note. J Gambl Stud 12: 471-473.

15. Lin YH, Chiang CL, Lin PH, Chang LR, Ko CH, et al. (2016) Proposed diagnostic criteria for smartphone addiction. PLoS One 11: e0163010.

16. Block JJ (2008) Issues for DSM-V: Internet addiction. Am J Psychiatry 165: 306-307.

17. Chen B, Liu F, Ding S, Ying X, Wang L, et al. (2017) Gender differences in factors associated with smartphone addiction: A cross-sectional study among medical college students. BMC Psychiatry 17: 341.

18. Brenner V (1997) Psychology of computer use: XLVII. Parameters of Internet use, abuse and addiction: The first 90 days of the internet usage survey. Psychol Rep 80: 879882

19. Young K, Pistner M, O'MARA J, Buchanan J (1999) Cyber disorders: The mental health concern for the new millennium. CyberPsychol Behav 2: 475-479.

20. Ko CH, Yen JY, Chen CC, Chen SH, Wu K, et al. (2006) Tridimensional personality of adolescents with internet addiction and substance use experience. Can J Psychiatry 51: 887-894.

21. Peng W, Liu M (2010) Online gaming dependency: A preliminary study in China. Cyberpsychol Behav Soc Netw 13 329-333.

22. Rehbein F, Kleimann M, Mössle T (2010) Prevalence and risk factors of video game dependency in adolescence: Results of a German nationwide survey. Cyberpsychol Behav Soc Netw 13: 269-277.

23. Dworak M, Schierl T, Bruns T, Strüder HK (2007) Impact of singular excessive computer game and television exposure on sleep patterns and memory performance of school-aged children. Pediatrics 120: 978-985

24. Chan PA, Rabinowitz T (2006) A cross-sectional analysis of video games and attention deficit hyperactivity disorder symptoms in adolescents. Ann Gen Psychiatry 5: 16.

25. Chiu SI, Lee JZ, Huang DH (2004) Video game addiction in children and teenagers in Taiwan. CyberPsychology Behav 7: $571-581$.

26. Hussain Z, Griffiths MD (2009) The attitudes, feelings, and experiences of online gamers: A qualitative analysis. CyberPsychology Behav 12: 747-753.

27. Hussain Z, Griffiths MD (2009) Excessive use of massively multi-player online role-playing games: A pilot study. Int $J$ Ment Health Addict 7: 563-571.
28. Lemmens JS, Valkenburg PM, Peter J (2011) Psychosocial causes and consequences of pathological gaming. Comput Human Behav 27: 144-152.

29. Choi NY, Han E (2006) Predictors of children's and adolescents' game addiction: Impulsivity, communication with parents and expectation about the internet games. J Korean Home Manag Assoc 24: 209-219.

30. Kim MO (2001) A study on the effects of family resilience of adoption of family of children with disabilities. Korean J Fam Soc Work 8: 939.

31. Young KS (1996) Psychology of computer use: XL. Addictive use of the Internet: A case that breaks the stereotype. Psychol Rep 79: 899-902.

32. Venkatesh E, Jemal MY, Samani AS (2017) Smart phone usage and addiction among dental students in Saudi Arabia: a cross sectional study. Int J Adolesc Med Health.

33. Kuss DJ, Griffiths MD (2011) Online social networking and addiction-a review of the psychological literature. Int J Environ Res Public Health 8: 3528-3552.

34. Kwon M, Lee JY, Won WY, Park JW, Min JA, et al. (2013) Development and validation of a smartphone addiction scale (SAS). PLoS One 8: e56936.

35. De-Sola Gutiérrez J, Rodríguez de Fonseca F, Rubio G (2016) Cell-phone addiction: A review. Front psychiatry 7: 175.

36. Darcin AE, Noyan C, Nurmedov S, Yilmazc O, Dilbazet N, et al. (2015) Smartphone addiction in relation with social anxiety and loneliness among university students in Turkey. Eur Psychiatry 30: 505.

37. Ching SM, Yee A, Ramachandran V, Sazlly Lim SM, Wan Sulaiman WA, et al. (2015) Validation of a Malay version of the smartphone addiction scale among medical students in Malaysia. PLoS One 10: e0139337.

38. Lee YK, Chang CT, Lin Y, Cheng ZH (2014) The dark side of smartphone usage: Psychological traits, compulsive behavior and technostress. Comput Human Behav 31: 373383.

39. Amidtaher M, Saadatmand S, Moghadam Z, Fathi G, Afshar R (2016) The relationship between mobile cellphone dependency, mental health and academic achievement. Am J Educ Res 4: 408-411.

40. Ganganahalli P, Tondare MB, Durgawale PM (2014) Use of electronic gadgets among medical students in western Maharashtra, India. Int J Heal Sci Res 4: 26-30.

41. North D, Johnston K, Ophoff J (2014) The use of mobile phones by South African university students. Issues Informing Sci Inf Technol 11: 115-138.

42. Roberts J, Yaya L, Manolis C (2014) The invisible addiction: Cell-phone activities and addiction among male and female college students. J Behav Addict 3: 254-265.

43. Salehan M, Negahban A (2013) Social networking on smartphones: When mobile phones become addictive. Comput Human Behav 29: 2632-2639.

44. Subba SH, Mandelia C, Pathak V, Reddy D, Goel A, et al. (2013) Ringxiety and the mobile phone usage pattern among the students of a medical college in South India. $J$ Clin Diagnostic Res 7: 205-209.

45. Demirci K, Akgönül M, Akpinar A (2015) Relationship of smartphone use severity with sleep quality, depression, and anxiety in university students. J Behav Addict 4: 85-92.

46. Pavithra MB, Madhukumar S, Mahadeva M (2015) A study 
on nomophobia-mobile phone dependence, among students of a medical college in Bangalore. Natl $\mathrm{J}$ community Med 6: 340-344.

47. Wood AW, Loughran SP, Stough C (2006) Does evening exposure to mobile phone radiation affect subsequent melatonin production? Int J Radiat Biol 82: 69-76.

48. Cain N, Gradisar M (2010) Electronic media use and sleep in school-aged children and adolescents: A review. Sleep Med 11: 735-742.

49. Loughran SP, Wood AW, Barton JM, Croft RJ, Thompson $B$, et al. (2005) The effect of electromagnetic fields emitted by mobile phones on human sleep. Neuroreport 16: 19731976.

50. Sheldon SH, Kryger MH, Ferber R, Gozal D (2014) Principles and practice of pediatric sleep medicine e-book. Elsevier Health Sciences.

51. Huber R, Treyer V, Borbely AA, Schuderer J, Gottselig JM, et al. (2002) Electromagnetic fields, such as those from mobile phones, alter regional cerebral blood flow and sleep and waking EEG. J Sleep Res 11: 289-295.

52. Thomée S, Härenstam A, Hagberg M (2011) Mobile phone use and stress, sleep disturbances, and symptoms of depression among young adults-a prospective cohort study. BMC Public Health 11: 66.

53. Lemola S, Perkinson-Gloor N, Brand S, Dewald-Kaufmann JF, Grob A (2015) Adolescents' electronic media use at night, sleep disturbance, and depressive symptoms in the smartphone age. J Youth Adolesc 44: 405-418

54. Hysing M, Pallesen S, Stormark KM, Jakobsen R, Lundervold AJ, et al. (2015) Sleep and use of electronic devices in adolescence: results from a large population-based study. BMJ Open 5: e006748.

55. Lanaj K, Johnson RE, Barnes CM (2014) Beginning the workday yet already depleted? Consequences of late-night smartphone use and sleep. Organ Behav Hum Decis Process 124: 11-23.
56. Arora T, Broglia E, Thomas GN, Taheri S (2014) Associations between specific technologies and adolescent sleep quantity, sleep quality, and parasomnias. Sleep Med 15: 240-247.

57. Scarpace PJ, Matheny M, Pollock BH, Tumer N (1997) Leptin increases uncoupling protein expression and energy expenditure. Am J Physiol Metab 273: E226-E230.

58. Van Cauter E, Spiegel K, Tasali E, Leproult R (2008) Metabolic consequences of sleep and sleep loss. Sleep Med 9: S23-S28.

59. Vaara J, Kyröläinen H, Koivu M, Tulppo M, Finni T (2009) The effect of 60-h sleep deprivation on cardiovascular regulation and body temperature. Eur J Appl Physiol 105: 439444.

60. Patel SR, Hu FB (2008) Short sleep duration and weight gain: A systematic review. Obesity Obesity (Silver Spring) 16: 643-653.

61. Schmid SM, Hallschmid M, Jauch-Chara K, Wilms B, Benedict C, et al. (2009) Short-term sleep loss decreases physical activity under free-living conditions but does not increase food intake under time-deprived laboratory conditions in healthy men. Am J Clin Nutr 90: 1476-1482.

62. Pannain S, Miller A, Van Cauter E (2008) Sleep loss, obesity and diabetes: Prevalence, association and emerging evidence for causation. Obesity and Metabolism 4: 28-41.

63. Spiegel K, Leproult R, L'Hermite-Balériaux M, Copinschi G, Penev PD, et al. (2004) Leptin levels are dependent on sleep duration: relationships with sympathovagal balance, carbohydrate regulation, cortisol, and thyrotropin. J Clin Endocrinol Metab 89: 5762-5771.

64. Spiegel K, Leproult R, Van Cauter E (1999) Impact of sleep debt on metabolic and endocrine function. Lancet 354 : $1435-1439$

65. Griffiths M (2000) Internet addiction-time to be taken seriously? Addict Res 8: 413-418. 